\title{
Kinetic Energy Release and Position of Transition State during Intramolecular Aromatic Substitution in Ionized 1-Phenyl-1-(2-pyridyl)ethylenes ${ }^{1}$
}

\author{
Ralf Schubert and Hans-Friedrich Grützmacher* \\ Contribution from the Fakultät für Chemie der Universität Bielefeld, \\ D-4800 Bielefeld 1, West Germany. Received September 4, 1979
}

\begin{abstract}
The loss of substituents ( $\left.\mathrm{X}=\mathrm{H}, \mathrm{F}, \mathrm{CH}_{3}, \mathrm{Cl}, \mathrm{Br}, \mathrm{I}\right)$ from the molecular ions of ortho-substituted 1-phenyl-1-(2pyridyl)ethylenes 1a-f and of the isomeric 1-phenyl-1-(3-pyridyl)- and 1-phenyl-1-(4-pyridyl)ethylenes 2 and 3 has been investigated. Cyclic fragment ions a are formed from the ortho-substituted 1-phenyl-1-(2-pyridyl)ethylene molecular ions by an intramolecular aromatic substitution reaction. The energetic requirements of this reaction have been studied in dependence from the dissociation energy of the $\mathrm{C}-\mathrm{X}$ bond by measurements of the ionization energies, appearance energies, and kinetic energies released during the reaction. The activation energy $\epsilon_{h}{ }^{*}$ of the process varies only slightly with the dissociation energy of the $C-X$ bond cleaved during the reaction, whereas the enthalpy of reaction changes from positive (endothermic) to very negative (exothermic) values in the reaction series $1 \mathrm{a}-\mathrm{f}$. Consequently the reverse activation energy $\epsilon_{\mathrm{r}}^{*}$ ranges from small to very large values in this series. This trend in $\epsilon_{\mathrm{r}}{ }^{*}$ is not followed by the kinetic-energy release. A large kinetic-energy release and energy partitioning quotient $q=0.7-1.0$ is only observed for endothermic or thermoneutral processes, while a small kinetic-energy release and $q \simeq 0.2$ is associated with exothermic reactions in spite of a large $\epsilon_{r}^{*}$. This behavior has been correlated to the position $X_{0}^{*}$ of the transition state on the reaction coordinate according to Miller's quantification of the Hammond postulate. The release of $\epsilon_{\mathrm{r}}^{*}$ as kinetic energy is only observed for reactions with "symmetrical" or "late" transition states $\left(X_{0}^{*}>0.4\right)$ while most of $\epsilon_{\mathrm{r}}{ }^{*}$ remains as internal energy in the products of reactions with "early" transition states $\left(X_{0}^{*}<0.4\right)$.
\end{abstract}

The investigations of metastable ions in a mass spectrometer have been shown to reveal many mechanistic details of unimolecular reactions of organic ions. ${ }^{2}$ The possibility of determining accurately the kinetic energy, $T,{ }^{3}$ released during unimolecular reactions, is especially important. $T$ stems from the potential energy of the transition state and the excess energy, $\epsilon^{*}$, freely fluctuating in the activated complex. The nonfixed excess energy of metastable ions is usually small, and, if there is an activation energy of the reversed reaction, ${ }^{0} \epsilon_{\mathrm{r}}^{*}$, the major part of $T$ often comes from ${ }^{0} \epsilon_{\mathrm{T}}{ }^{*},{ }^{3,4}$ In this case, ${ }^{0} \epsilon_{\mathrm{r}}{ }^{*}$ can be approximated by the experimental activation energy of the reversed reaction, $\epsilon_{\mathrm{r}}^{*}$, which is derived from the appearance energy of the reaction and the sum of the heats of formation of the reaction products and which includes a small amount of nonfixed energy, $\epsilon^{*}$, due to the kinetic shift of the appearance energy. The amount of $\epsilon_{\mathrm{r}}^{*}$, which appears as kinetic energy $T$ in the products, can be expressed by the energy partitioning quotient $q=T / \epsilon_{\Gamma}^{*}$. The value of $q$ depends obviously on the details of the energy hypersurface of the reaction in the neighborhood of the transition state. This has been shown for the elimination of $\mathrm{H}_{2}$ and other small molecules from even-electron organic ions. ${ }^{2,5,6}$ The prerequisite for a large kinetic energy release during these reactions is not only a large ${ }^{0} \epsilon_{\mathrm{r}}^{*}$, but also a certain geometry of the activated complex, which allows channeling of its potential energy into translational energy of the products during the movement of the reaction system along the reaction coordinate. ${ }^{5,6}$ Hence a determination of $q$ and its variation with structural changes in the reaction system offers the possibility of

(1) Mechanism of Mass Spectrometric Fragmentation Reactions. 26. Part 25: Schubert, R.; Grützmacher, H. F. Org. Mass Spectrom. 1980, 15, 122 (2) Williams, D. H. Acc. Chem. Res. 1977, 10, 280 and references cited therein.

(3) Cooks, R. G.; Beynon, J. H.; Caprioli, R. M.; Lester, G. R "Metastable Ions"; Elsevier: Amsterdam, 1973.

(4) Cooks, R. G.; Bertrans, M.; Beynon, J. H.; Rennekamp, M. E.; Setser, D. W. J. Am. Chem. Soc. 1973, 95, 1732.

(5) (a) Christie, J. R.; Derrick. P. J.; Richard. G. J. J. Chem. Soc., Faraday Trans. 2 1978, 74, 304. (b) Rickard, G. J.; Cole, N. W.; Christie, J. R.; Derrick, P. J. J. Am. Chem. Soc. 1978, 100, 2804. (c) Cole, N. W. Rickard, G. J.; Christie, J. R.; Derrick, P. J. Org. Mass Spectrom. 1979, 14, 337

(6) (a) Krause, D. A.; Day, R. J.; Jorgensen, W. L.; Cooks, R. G. Int. J. Mass Spectrom. Ion Phys. 1978, 27, 227. (b) Day, R. J.; Krause, D. A Jorgensen, W. L.; Cooks, R. G. Ibid. 1979, 30,83.
Scheme I

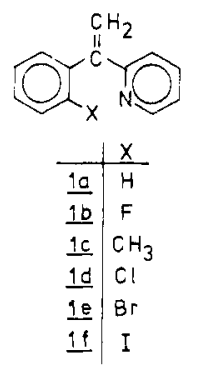

Scheme II
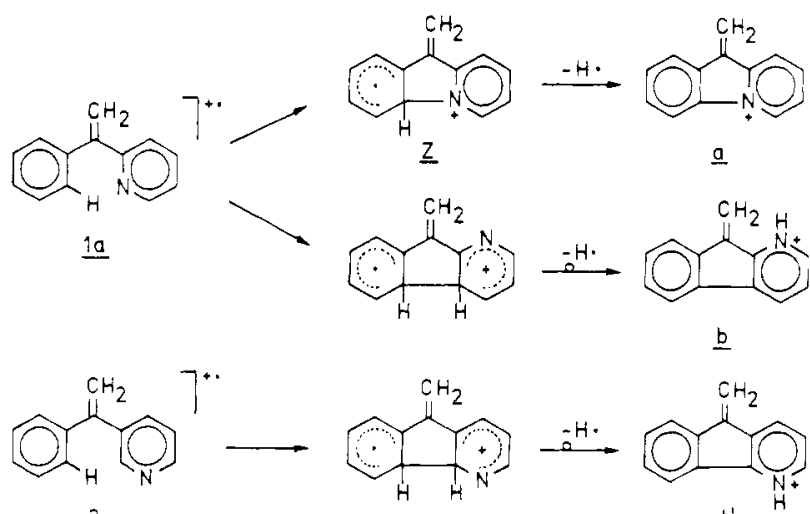

$\underline{2}$

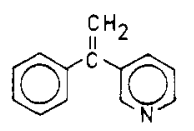

$\underline{2}$

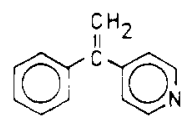

$\underline{3}$
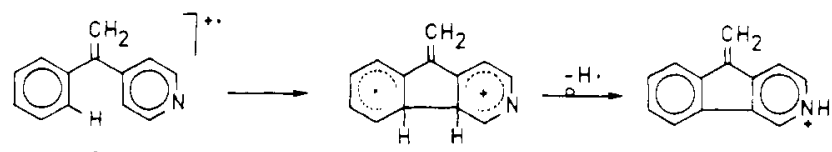

3

$\underline{b^{*}}$

observing some properties of the transition states of rather complex organic reactions directly.

In this paper the loss of ortho substituents at the phenyl group from molecular ions of substituted 1-phenyl-1-(2-pyridyl)ethylenes (1a-f, Scheme I) is discussed. Formally, this fragmentation corresponds to simple bond cleavage in an odd-electron ion, a frequently observed mass-spectrometric reaction. Its mechanism, 
Table 1. Partial 70-eV Mass Spectra ${ }^{a}$ of

1-Phenyl-1-pyridylethylenes and Substituted Derivatives

\begin{tabular}{|c|c|c|c|c|c|c|c|c|}
\hline$m / z$ & $1 \mathrm{a}$ & $1 b$ & $1 \mathrm{c}$ & $1 d$ & le & 1f & 2 & 3 \\
\hline $\mathrm{M}$ & 15 & 30 & 52 & 1 & $<1$ & $<1$ & 65 & 84 \\
\hline$M-1$ & & 70 & 73 & 6 & 3 & $<1$ & & \\
\hline $\mathrm{M}-2$ & & 3 & 16 & & & & & \\
\hline$M-3$ & & 4 & 15 & & & & & \\
\hline$M-4$ & & & 9 & & & & & \\
\hline $180(M-X)$ & 100 & 100 & 100 & 100 & 100 & 100 & 100 & 100 \\
\hline 179 & 4 & 7 & 7 & 3 & 5 & 6 & 6 & 4 \\
\hline 178 & 7 & 11 & 7 & 7 & 9 & 11 & 8 & 6 \\
\hline 177 & 1 & 3 & 2 & 2 & 2 & 2 & 2 & 2 \\
\hline 166 & & & & & & & 23 & 10 \\
\hline 153 & 2 & 1 & 2 & 1 & 2 & 2 & 9 & 17 \\
\hline 152 & 17 & 9 & 13 & 8 & 11 & 17 & 35 & 41 \\
\hline 151 & 6 & 8 & 5 & 4 & 5 & 8 & 14 & 15 \\
\hline 150 & 2 & 3 & 1 & 1 & 1 & 3 & 4 & 4 \\
\hline 140 & & & & & & & 3 & 2 \\
\hline 139 & & & & & & & 5 & 5 \\
\hline 128 & 1 & 1 & 3 & 1 & 1 & 2 & 2 & 3 \\
\hline 127 & 3 & 1 & 2 & 2 & 2 & 3 & 6 & 9 \\
\hline 126 & 1 & 2 & 1 & 1 & 1 & 3 & 4 & 4 \\
\hline 115 & & & & & & & 3 & 4 \\
\hline 114 & & & & & & & 1 & 1 \\
\hline 113 & & & & & & & 2 & 1 \\
\hline 102 & 2 & 5 & 1 & 1 & 2 & 3 & 5 & 6 \\
\hline 101 & 1 & 2 & 1 & 3 & 2 & 3 & 2 & 2 \\
\hline 90 & 4 & 3 & 5 & 2 & 5 & 9 & 6 & 5 \\
\hline 89.5 & 1 & 3 & - & 4 & 2 & 2 & 4 & 5 \\
\hline 89 & 3 & 4 & 5 & 3 & 2 & 1 & 6 & 6 \\
\hline 79 & 2 & 4 & 6 & 1 & 1 & 1 & 1 & 1 \\
\hline 78 & 4 & 8 & 6 & 4 & 4 & 5 & 4 & 4 \\
\hline 77 & 10 & 4 & 5 & 3 & 4 & 9 & 16 & 22 \\
\hline 76 & 3 & 3 & 2 & 2 & 2 & 5 & 10 & 13 \\
\hline 75 & 2 & 7 & 2 & 3 & 2 & 4 & 5 & 5 \\
\hline 63 & 2 & 2 & 3 & 1 & 1 & 3 & 6 & 7 \\
\hline 52 & 4 & 8 & 5 & 1 & 2 & 3 & 3 & 4 \\
\hline 51 & 5 & 8 & 5 & 4 & 4 & 8 & 12 & 14 \\
\hline 50 & 2 & 3 & 2 & 1 & 1 & 3 & 5 & 5 \\
\hline
\end{tabular}

${ }^{a}$ Intensities in \% base peak; peaks indicated represent $>80 \%$ total ion current.

however, is better described as an intramolecular aromatic substitution reaction. ${ }^{7,8}$ In contrast to some other fragmentations of odd-electron aromatic molecular ions,${ }^{4}$ for which constant energy partitioning is observed, the energy partitioning quotient $q$ varies drastically with the nature of the substituent lost. It will be shown that the variation of $q$ can be related to the position of the transition state at the reaction coordinate expressed by $X_{0}{ }^{*}$, a function given by Miller" for a "quantitative Hammond Postulate".

\section{Results and Discussion}

Mass Spectra and Structure of $\boldsymbol{m} / \boldsymbol{z} 180$ Ions. The $70-\mathrm{eV}$ mass spectra of 1,1-diphenylethylene, 1-phenyl-1-(2-pyridyl)ethylene (1a), 1-phenyl-1-(3-pyridyl)ethylene (2), and 1-phenyl-1-(4pyridyl)ethylene (3) (Table I) contain only a few intense signals due to fragment ions. While loss of a methyl radical is the predominant reaction of 1,1-diphenylethylene molecular ions besides loss of $\mathrm{H}$ and $\mathrm{H}_{2}$, its aza analogues 1a, 2, and 3 fragment predominantly by loss of $\mathrm{H}$, followed by elimination of $\mathrm{CH}_{2} \mathrm{~N}$, to ions $\mathrm{m} / \mathrm{z} 180$ and 152 , respectively.

The predominance of $[\mathrm{M}-\mathrm{H}]^{+}$ions $(m / z 180)$ as primary fragmentation products is most easily explained by the formation of stable cyclic ions $\mathrm{b}^{\prime}$ and $\mathrm{b}^{\prime \prime}$ from $\mathbf{2}^{+}$. and $\mathbf{3}^{+}$, respectively, and $b$ or a from $\mathbf{1 a}^{+}$. (Scheme II). The reduced intensity of the molecular ions and the increased intensity of the $[\mathrm{M}-\mathrm{H}]^{+}$ions in the mass spectrum of 1 a suggest that the formation of ions a,

(7) Schaldach, B.; Grützmacher, H. F. Int. J. Mass Spectrom. Ion Phys 1979, 31, 257.

(8) (a) Ronayne, J.; Williams, D. H.; Bowie, J. J. Am. Chem. Soc. 1966 88,4980 . (b) Kuschel, H.; Grützmacher, H. F. Org. Mass Spectrom. 1974, 9,408 .

(9) Miller, A. R. J. Am. Chem. Soc. 1978, 100, 1984.
Table II. MI Spectra of $[\mathrm{M}-\mathrm{X}]^{+}$Ions $(\mathrm{m} / \mathrm{z} 180 ; 70 \mathrm{eV})$

\begin{tabular}{lcrrrrrr}
\hline$m / z$ & 1a & 1b & 1c & 1d & 1f & 2 & 3 \\
\hline $179^{a}$ & $(583)$ & $(259)$ & $(194)$ & $(205)$ & $(176)$ & $(398)$ & $(260)$ \\
178 & 39 & 40 & 40 & 41 & 43 & 35 & 36 \\
177 & 1 & 1 & 1 & 1 & 1 & & \\
153 & 27 & 18 & 19 & 19 & 14 & 49 & 61 \\
152 & 28 & 35 & 34 & 35 & 36 & 16 & 13 \\
151 & 5 & 6 & 6 & 5 & 6 & & \\
\hline
\end{tabular}

${ }^{a}$ Omitted from normalization. ${ }^{12}$

Table III. CA Spectra of $[\mathrm{M}-\mathrm{X}]^{+}$Ions $(\mathrm{m} / \mathrm{z} 180 ; 70 \mathrm{eV})$

\begin{tabular}{lcccccc}
\hline \multicolumn{1}{c}{$m / z$} & $\mathbf{1 a}$ & $\mathbf{1 b}$ & \multicolumn{1}{c}{$\mathbf{1 c}$} & $\mathbf{1 f}$ & $\mathbf{2}$ & $\mathbf{3}$ \\
\hline $179^{a}$ & $(108)$ & $(115)$ & $(86)$ & $(94)$ & $(81)$ & $(60)$ \\
$178^{a}$ & $(130)$ & $(145)$ & $(121)$ & $(128)$ & $(89)$ & $(72)$ \\
177 & 26 & 28 & 26 & 27 & 24 & 21 \\
176 & 6 & 6 & 6 & 6 & 5 & 5 \\
$164-166$ & 4 & 6 & 4 & 4 & 3 & 2 \\
$152-153^{a}$ & $(53)$ & $(49)$ & $(47)$ & $(47)$ & $(86)$ & $(88)$ \\
$151^{a}$ & $(32)$ & $(30)$ & $(30)$ & $(31)$ & $(47)$ & $(50)$ \\
150 & 14 & 12 & 13 & 13 & 20 & 24 \\
$137-139$ & 6 & 6 & 6 & 6 & 8 & 8 \\
$125-128$ & 10 & 10 & 10 & 6 & 12 & 12 \\
$112-114$ & 3 & 3 & 2 & 3 & 4 & 3 \\
$99-101$ & 8 & 7 & 8 & 9 & 6 & 6 \\
$86-89$ & 3 & 3 & 2 & 3 & 3 & 3 \\
$75-77$ & 11 & 12 & 12 & 13 & 10 & 9 \\
$62-63$ & 3 & 3 & 5 & 4 & 4 & 4 \\
$50-51$ & 5 & 6 & 6 & 6 & 3 & 3
\end{tabular}

${ }^{a}$ Omitted from normalization.

which are unique for 1a, occurs with special ease. This is corroborated by the mass spectra of derivatives substituted at the phenyl group of 1a, which show large peaks due to loss of the substituent $\mathrm{X}$ from the molecular ions only for the ortho isomers 1b-f (see Table I and Figure 1).

The loss of a hydrogen atom or the substituent $\mathrm{X}$ and formation of $\mathrm{m} / \mathrm{z} 180$ ions is the only reaction observed for metastable molecular ions of 1a-f, being obviously the only low-energy reaction path of these ions. The structures of the ions $[\mathrm{M}-\mathrm{X}]^{+}$ $(\mathrm{m} / \mathrm{z} 180)$ in the mass spectra of $\mathbf{1 a}-\mathbf{f}, \mathbf{2}$, and $\mathbf{3}$ have been studied by their unimolecular and collisional induced decompositions in the field-free region between the magnetic and electrostatic analyzer (second field-free region) of a VG ZAB $2 F$ mass spectrometer using the DADI technique. ${ }^{10}$

All metastable $m / z 180$ ions formed in the $70-\mathrm{eV}$ mass spectra of $1 \mathrm{a}-\mathrm{f}, 2$, and 3 decompose by losses of $\mathrm{H}, \mathrm{H}_{2}, \mathrm{HCN}, \mathrm{CH}_{2} \mathrm{~N}$, and $\mathrm{CH}_{3} \mathrm{~N}$ to product ions $m / z 179,178,153,152$, and 151 , respectively ${ }^{11}$ (Table II).

The intensity pattern of the product ions of $m / z 180$ ions are identical within the limits of error for the ortho-substituted derivatives $\mathbf{1 b}-\mathbf{f}$, which are expected to fragment to ions $\mathrm{a} .{ }^{13}$ The $\mathrm{m} / \mathrm{z} 180$ ions arising from $\mathbf{2}$ and $\mathbf{3}$ differ clearly by a much larger

(10) (a) Beynon, J. H.; Caprioli, R. M.; Ast, T. Org. Mass Spectrom. 1971, 5, 229. (b) Maurer, K. H.; Brunnẻe, C.; Kappus, G.; Habfast, K.; Schröder, U.; Schulze, P. XIX Annual Conference on Mass Spectrometry and Allied Topics, Atlanta, Ga., 1971.

(11) As can be seen from the abnormal peak shapes, the signal at $m / z 179$ in the MI spectra of $\mathrm{m} / z 180$ ions from 1a, 2 , and $\mathbf{3}$ is composite and contains an interference peak besides the peak of $(180-\mathrm{H})$ ions. This interference peak stems from a metastable transition $182^{+} \rightarrow 181^{+}$occurring in the first field-free region and corresponding to loss of $\mathrm{H}$ from ${ }^{13} \mathrm{C}$ molecular ions of 1a, 2 , and 3 , which is transmitted by the instrument. ${ }^{12}$ Hence the intensity of the signal at $\mathrm{m} / z 179$ has to be excluded from a comparison of the MI spectra.

(12) Schaldach, B.; Grützmacher, H. F. Org. Mass Spectrom., 1980, 15, 166

(13) The $m / z 180$ ions in the mass spectra of $1 \mathrm{a}-\mathbf{f}$ are formed with a wide range of internal energies. This follows from the energetics of the fragmentations. It is of interest to note that this has no large effect on the intensity distribution of the product ions in the MI spectra. However, the total ion current of the MI spectra relative to the ion current of the mother ion is much less for $m / z 180$ ions from $1 \mathbf{a}-\mathrm{c}$ than from $1 \mathbf{d}-\mathbf{f}$. The latter ions must contain a larger amount of excess energy than the former ones, which have been formed with a larger kinetic-energy release. 

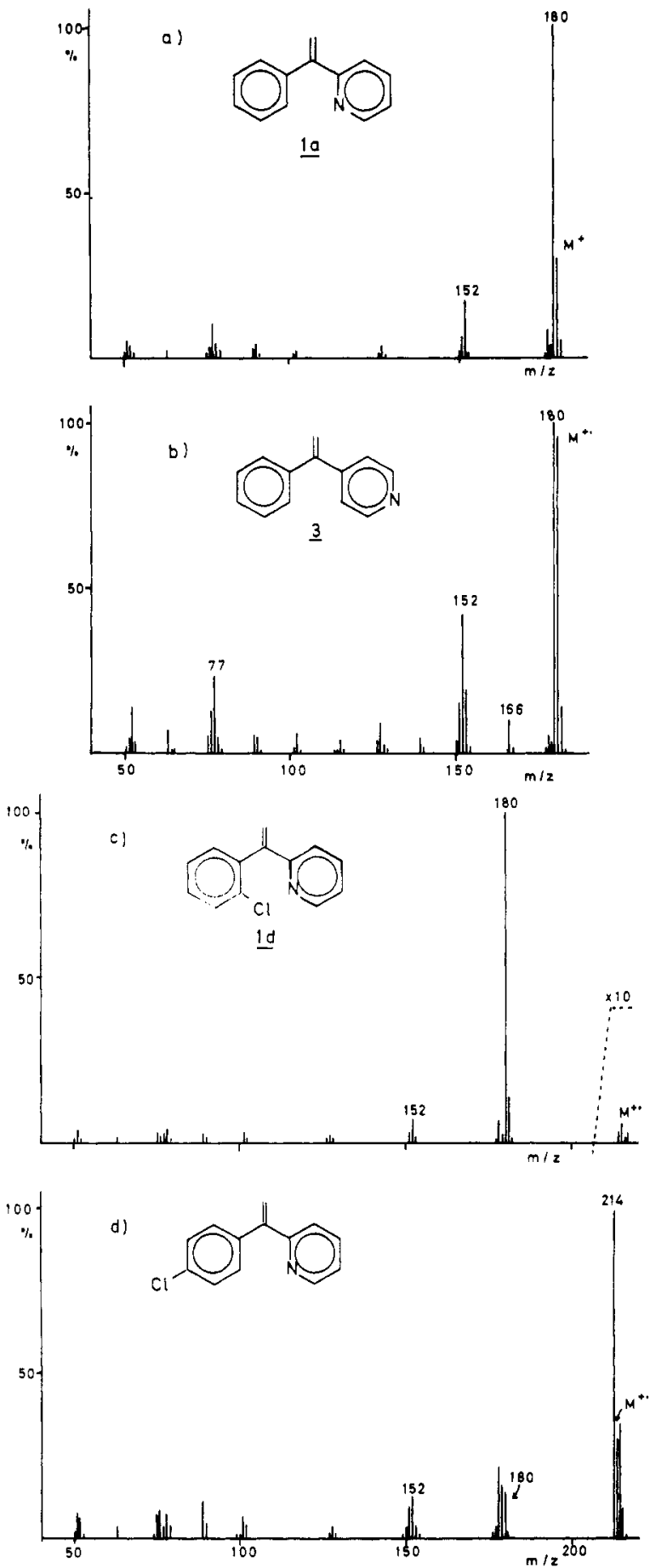

Figure 1. The 70-eV mass spectra of (a) 1-phenyl-1-(2-pyridyl)ethylene (1a), (b) 1-phenyl-1-(4-pyridyl)ethylene (3), (c) 1-(2-chlorophenyl)1-(2-pyridyl)ethylene (1d), (d) 1-(4-chlorophenyl)-1-(2-pyridyl)ethylene.

intensity of $\mathrm{m} / z 153$ product ions, indicating a different structure (probably $\mathrm{b}^{\prime}$ and $\mathrm{b}^{\prime \prime}$ ). No clear decision can be made for $\mathrm{m} / \mathrm{z}$ 180 ions formed in the $70-\mathrm{eV}$ mass spectrum of 1a, however, since the intensity pattern falls between that observed for $\mathbf{1 b}$ and $\mathbf{1 f}$ and 2 and 3, respectively, but likely metastable $\mathrm{m} / z 180$ ions from 1a represent a mixture of structures $a$ and $b$.

The CA spectra of the $m / z 180$ ions from the $70-\mathrm{eV}$ mass spectra of $1 \mathrm{a}-\mathrm{f}, \mathbf{2}$, and $\mathbf{3}$ contain signals of additional product ions, although with rather small intensities (Table III). As expected from the similar structures of the $m / z 180$ ions, the CA spectra are qualitatively similar. However, the intensity distribution in these CA spectra are identical only for $m / z 180$ ions arising from 1a-f (including the parent compound 1a) and are distinguished from those of 2 and 3 .

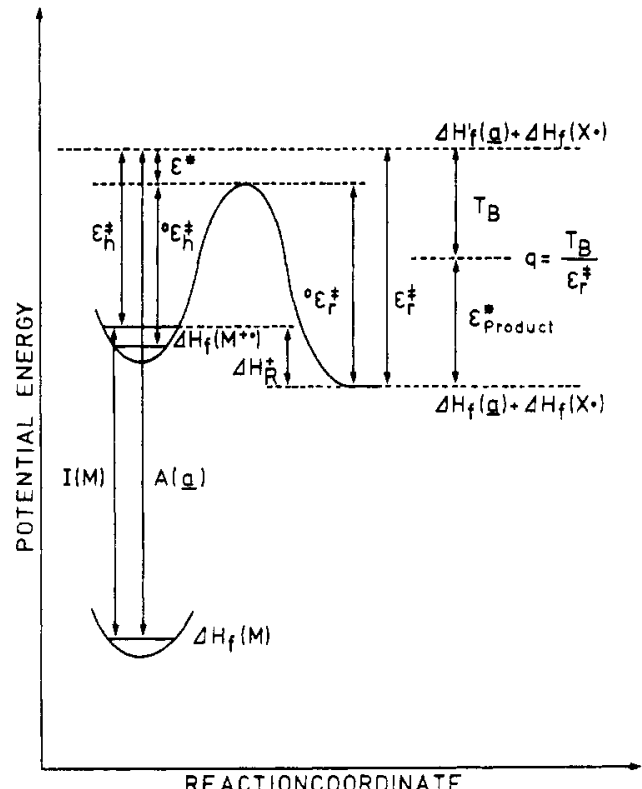

Figure 2. Potential-energy diagram of a unimolecular mass spectrometric fragmentation: $I(\mathrm{M})=$ ionization energy; $A(\mathrm{a})=$ appearance energy of ion a: $\Delta H_{\mathrm{R}}{ }^{+}=$reaction enthalpy; $\Delta H_{f}\left(\mathrm{M}^{+}\right.$.), $\Delta H_{\mathrm{f}}(\mathrm{a}), \Delta H_{\mathrm{f}}(\mathrm{X} \cdot)=$ heat of formation of $\mathrm{M}, \mathrm{a}$, and $\mathrm{X} \cdot ; \Delta H_{\mathrm{f}}^{\prime}(\mathrm{a})=$ apparent heat of formation of ion $\mathrm{a}:{ }^{0} \mathrm{\epsilon}_{\mathrm{b}}{ }^{*}=$ thermochemical activation energy of the forward reaction; $\epsilon_{\mathrm{h}}{ }^{*}=$ experimental activation energy of the forward reaction; $\epsilon^{*}=$ nonfixed excess energy of the activated complex; ${ }^{0} \epsilon_{\mathrm{r}}^{*}=$ thermochemical reverse activation energy; $\epsilon_{\mathrm{r}}^{*}=$ experimental reverse activation energy; $T_{\mathrm{B}}=$ maximum kinetic energy release; $\epsilon^{*}{ }_{\text {product }}=$ excess internal energy of products; $q=$ energy partitioning quotient.

Table IV. Ionization Energy $I(\mathrm{M})$, Appearance Energy $A\left(180^{+}\right)$ Activation Energy $\epsilon_{\mathrm{h}}{ }^{\ddagger}$, Apparent Heat of Formation $\Delta H_{\mathrm{f}}^{\prime}\left(180^{+}\right)$ and Corrected Heat of Formation $\Delta H_{\mathrm{f}}^{\prime}\left(180^{+}\right)_{\text {cor }}$

\begin{tabular}{|c|c|c|c|c|c|}
\hline $\begin{array}{l}\text { substituent } \\
X\end{array}$ & $I(\mathrm{M})^{\circ}$ & $\begin{array}{c}A^{-} \\
{\left[(\mathrm{M}-\mathrm{X})^{+}\right]^{a}}\end{array}$ & $\epsilon_{\mathrm{h}} \neq a$ & $\frac{\Delta H_{\mathrm{f}}^{\prime}-}{\left[(\mathrm{M}-\mathrm{X})^{+}\right]^{b}}$ & $\begin{array}{c}\Delta H_{\mathrm{f}}^{\prime} \\
{\left[(\mathrm{M}-\mathrm{X})^{+}\right]_{\mathrm{cor}}}\end{array}$ \\
\hline H (1a) & 8.65 & $\begin{array}{c}9.5 \\
(9.3)\end{array}$ & $\begin{array}{c}0.8 \\
(0.6)\end{array}$ & $\begin{array}{c}237 \\
(232)\end{array}$ & $\begin{array}{l}225 \\
(220)\end{array}$ \\
\hline $\begin{array}{l}o-F(1 \mathrm{~b}) \\
p-F\end{array}$ & $\begin{array}{l}8.66 \\
8.68\end{array}$ & 9.5 & 0.7 & 223 & 220 \\
\hline $\begin{array}{l}o-\mathrm{CH}_{3}(1 \mathrm{c}) \\
m-\mathrm{CH}_{3}\end{array}$ & $\begin{array}{l}8.55 \\
8.48\end{array}$ & $\begin{array}{l}9.2 \\
9.7\end{array}$ & $\begin{array}{l}0.6 \\
1.2\end{array}$ & 241 & 224 \\
\hline $\begin{array}{l}p-\mathrm{CH}_{3} \\
o-\mathrm{Cl}(1 \mathrm{~d})\end{array}$ & $\begin{array}{r}8.45 \\
(8.6)^{c}\end{array}$ & $\begin{array}{l}9.8 \\
9.1\end{array}$ & $\begin{array}{l}1.3 \\
0.5\end{array}$ & 245 & 241 \\
\hline $\mathrm{p}-\mathrm{Cl}$ & 8.58 & 9.9 & 1.3 & & \\
\hline$\sigma-\mathrm{Br}(1 \mathrm{e})$ & $(8.6)^{c}$ & 9.0 & 0.4 & 260 & 253 \\
\hline $\begin{array}{l}p-B r \\
O-I(1 f)\end{array}$ & $\begin{array}{r}8.62 \\
(8.3)^{c}\end{array}$ & $\begin{array}{l}9.7 \\
8.8\end{array}$ & $\begin{array}{l}1.1 \\
0.5\end{array}$ & 269 & 261 \\
\hline$m-\mathrm{OCH}_{3}$ & 8.27 & & & & \\
\hline $\mathrm{p}-\mathrm{OCH}_{3}$ & 8.15 & & & & \\
\hline$m-\mathrm{CF}_{3}$ & $\begin{array}{l}9.02 \\
8.97\end{array}$ & & & & \\
\hline${ }_{2}^{p-C F_{3}}$ & $\begin{array}{l}8.97 \\
8.73\end{array}$ & 9.9 & 1.2 & 248 & 234 \\
\hline 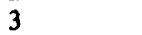 & 8.90 & 10.0 & 1.1 & 249 & 235 \\
\hline
\end{tabular}

${ }^{a} \mathrm{eV} .{ }^{b} \mathrm{kcal} \mathrm{mol}^{-1}$. ${ }^{c}$ Estimated from Hammett plot.

This result corroborates the conclusion, drawn from the MI spectra, that $\mathbf{1 b}-\mathbf{f}$ form identical ions $a, m / z 180$. Furthermore, it shows that most of the stable $\mathrm{m} / \mathrm{z} 180$ ions in the mass spectrum of $1 \mathrm{a}$ are also of structure a. ${ }^{14}$ These results show that the formation of $\mathrm{m} / \mathrm{z} 180$ ions from 1a-f mainly corresponds to the reaction $1 \mathrm{i} \rightarrow \mathrm{Z} \rightarrow$ a (Scheme II) and that this intramolecular

(14) It is seen from Table III that large differences in the CA spectra of the two types of $m / z 180$ ions are observed for product ions $\mathrm{m} / \mathrm{z} 151-153$ formed by unimolecular decompositions. These differences persist in the CA spectra of $m / z 180$ ions, generated by impact with low-energy electrons $(<15$ $\mathrm{eV}$ ) and stable toward unimolecular decompositions. Hence, these differences are very likely to reflect also structural differences of the $\mathrm{m} / \mathrm{z} 180$ ions and not only different internal energies. 


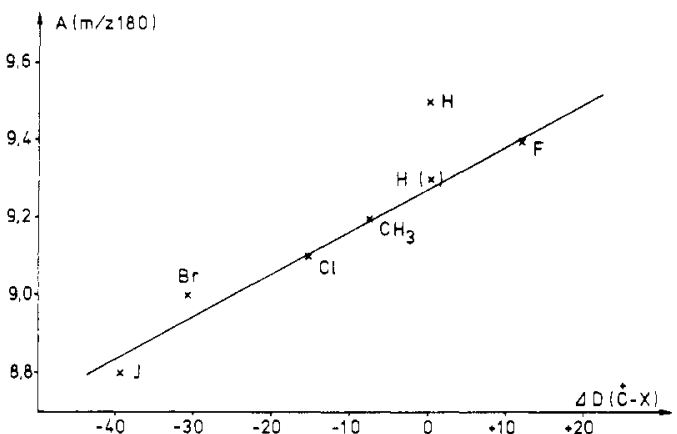

Figure 3. Dependence of appearance energy $A(a)$ on relative dissociation energy $\Delta D\left({ }^{+} \mathrm{C}-\mathrm{X}\right)$.

substitution reaction can be investigated without much interference by other fragmentations at least in the case of $\mathbf{1 b}-\mathbf{f}$.

Energetics of the Fragmentation. The potential-energy diagram of a mass-spectrometric fragmentation and the energetic quantities involved are shown schematically in Figure 2.

The ionization energies $(I(\mathrm{M}))$ of $1 \mathbf{a}-\mathbf{c}, 2$, and 3 and of some para- and meta-substituted derivatives of $1 \mathrm{a}$ are given in Table IV together with the appearance energies $A(\mathrm{~m} / z 180)$ of $\mathrm{m} / z 180$ ions. The $I(\mathrm{M})$ 's of phenyl-substituted 1-phenyl-1-(2-pyridyl)ethylenes correlate linearly with $\sigma_{\mathrm{IP}}{ }^{+}$constants ${ }^{15}\left(I(\mathrm{M})=0.64 \sigma_{\mathrm{IP}}{ }^{+}\right.$ $+8.7)$. The position of the substituent at the phenyl group has only a negligible influence on the $I(\mathrm{M})$, even at the ortho position, and this observation has been used to estimate the $I(\mathrm{M})$ 's of $1 \mathbf{d}-\mathbf{f}$, which have not been determined experimentally because of the low intensities of the molecular ions.

The $A\left(\mathrm{~m} / z 180^{+}\right)$values decrease in the series $1 \mathbf{b}-\mathrm{f}$ with the difference of the dissociation energies $\Delta D\left({ }^{+} \mathrm{C}-\mathrm{X}\right)$ of the substituent in the molecular ions ${ }^{16}$ (Figure 3 ). The exception is the parent compound 1a. Although $\boldsymbol{A}\left(\mathrm{m} / \mathrm{z} 180^{+}\right)$of $1 \mathrm{a}$ is below that of 2 and 3 , it appears to be too large by $0.2 \mathrm{eV}$ to follow the correlation. One usually observes some mean value by the experimental method used, if isobaric fragment ions with different structures and different appearance energies are formed. ${ }^{17}$ Hence the deviation of $A\left(\mathrm{~m} / z 180^{+}\right)$from 1 a can be explained by the formation of ions $\mathrm{b}$ with a larger $A\left(m / z 180^{+}\right)$besides ions a, in line with the results of the structure investigations of $m / z 180$ ions. In the following discussion data calculated with $A(\mathrm{a})=9.3 \mathrm{eV}$ from $1 \mathrm{a}$ are therefore included for comparison.

The apparent heat of formation of ion a, $\Delta H_{\mathrm{f}}^{\prime}(\mathrm{a})$, can be calculated by eq 1 , using the $A(\mathrm{a})$ from $1 \mathrm{a}-\mathrm{f}$, the $\Delta H_{\mathrm{f}}(\mathrm{M})$ of the neutral precursor molecules, and the $\Delta H_{\mathrm{f}}(\mathrm{X})$ of the radicals ${ }^{18}$ lost during the fragmentation. $\Delta H_{\mathrm{f}}(\mathrm{M})$ 's have been obtained by incremental methods ${ }^{19}$ using $\Delta H_{\mathrm{f}}(1,1$-diphenylethylene $)=58.7 \pm$ $1.1 \mathrm{kcal} \mathrm{mol}^{-120}$ as a starting point. $\Delta H_{\mathrm{f}}^{\prime}(\mathrm{a})$ (Table IV) includes the activation energy of the reverse reaction, $\epsilon_{\mathrm{r}}^{*}$, which can be (partly) corrected for by the maximum amount of kinetic energy, $T_{\mathrm{B}}$, released during the reaction according to eq 2 .

$$
\Delta H_{\mathrm{f}}^{\prime}(\mathrm{a})=A(\mathrm{a})+\Delta H_{\mathrm{f}}(\mathrm{M})-\Delta H_{\mathrm{f}}(\mathrm{X} \cdot)=\Delta H_{\mathrm{f}}(\mathrm{a})+\epsilon_{\mathrm{f}}^{*}
$$

$$
\Delta H_{f}^{\prime}(\mathrm{a})_{\text {cor }}=\Delta H_{f}^{\prime}(\mathrm{a})-T_{\mathrm{b}} \geq \Delta H_{\mathrm{f}}(\mathrm{a})
$$

(15) (a) Harrison, A. G.; Kebarle, P.; Lossing, F. P. J. Am. Chem. Soc. 1961, 83,777. (b) Bursey, M. M. Org. Mass Spectrom. 1968, I, 31. (c) Bentley, T. W.: Johnstone, R. A. W. J. Chem. Soc. B 1971, 263.

(16) $D\left({ }^{+} \mathrm{C}-\mathrm{X}\right)$ corresponds to the reaction $\mathrm{XC}_{6} \mathrm{H}_{4} \mathrm{C}\left(\mathrm{CH}_{2}\right) \mathrm{C}_{5} \mathrm{H}_{3} \mathrm{~N}^{+}$. (1i) $\rightarrow{ }^{+} \mathrm{C}_{6} \mathrm{H}_{4} \mathrm{C}\left(\mathrm{CH}_{2}\right) \mathrm{C}_{5} \mathrm{H}_{3} \mathrm{~N}+\mathrm{X}$. Since $\left.\Delta \mathrm{H}_{6}{ }^{+} \mathrm{C}_{6} \mathrm{H}_{4} \mathrm{C}\left(\mathrm{CH}_{2}\right) \mathrm{C}_{5} \mathrm{H}_{3} \mathrm{~N}\right)$ of the ion (with a positive charge at one of the $\mathrm{C}$ atoms of the phenyl group) is no known, the dissociation energies $\Delta D\left({ }^{+} \mathrm{C}-\mathrm{X}\right)$ relative to the unsubstituted $1 \mathbf{a}^{+} \cdot(\mathrm{X}=\mathrm{H})$ have been calculated by $\Delta D\left({ }^{+} \mathrm{C}-\mathrm{X}\right)=\Delta H_{\mathrm{f}}\left(\mathrm{X}_{\mathrm{i}}\right)-\Delta H_{\mathrm{f}}(\mathrm{H})+$ $\Delta H_{\mathrm{f}}\left(1 \mathrm{a}^{+} \cdot\right)-\Delta H_{\mathrm{f}}\left(1 \mathrm{i}^{+} \cdot\right)$

(17) Occolowitz, J. L.; Cerimele, B. J.; Brown, P. Org. Mass Spectrom $1974,8,61$.

(18) Rosenstock, H. M.; Draxl, K.; Steiner, B. W.; Herron, J. T. J. Phys. Chem. Ref. Data, Suppl. I 1977, 6 .

(19) Benson, S. W.; Cruickshank, F. R.; Golden, D. M.; Haugen, G. R.; O'Neal, H. E.; Rodgers, A. S.; Shaw, R.; Walsh, R. Chem. Rev. 1969, 69, 279.

(20) Cox, J. D.; Pilcher, G. "Thermochemistry of Organic and Organometallic Compounds"; Academic Press: New York, 1970.

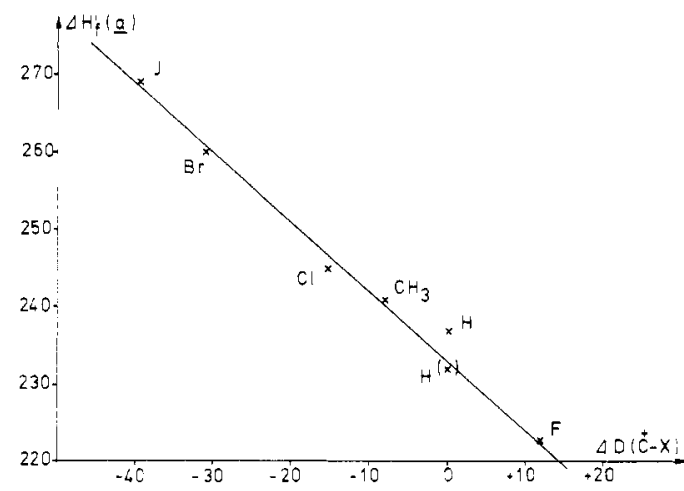

Figure 4. Dependence of apparent heat of formation $\Delta H_{f}^{\prime}(a)$ on relative dissociation energy $\Delta D\left({ }^{+} \mathrm{C}-\mathrm{X}\right)$.

Table V. Reaction Enthalpy $\Delta H_{\mathrm{R}}{ }^{+}$, Reverse Activation Energy $\epsilon_{\mathrm{r}}{ }^{\ddagger}$, Released Kinetic Energy $T$, Energy Partitioning Quotient $q$, and Position of Transition State $X_{\mathrm{o}}$ * of the Intramolecular Substitution of 1-Phenyl-1-(2-pyridyl)ethylene Molecular Ions

\begin{tabular}{rcccccccc}
\hline & & & & \multicolumn{2}{c}{$T_{22} /$} & & \\
& $\Delta H_{\mathrm{R}}{ }^{a}$ & $\epsilon_{\mathrm{r}}{ }^{\ddagger a}$ & $T_{22}{ }^{b}$ & $T_{50}{ }^{b}$ & $T_{50}$ & $T_{\mathrm{B}}{ }^{a}$ & $q$ & $X_{\mathrm{o}}{ }^{*}$ \\
\hline 1a & +2 & 17 & 420 & 300 & 1.40 & 12 & 0.71 & 0.53 \\
& & $(12)$ & & & & & $(1.0)$ & $(0.54)$ \\
lb & +14 & 3 & 87 & 42 & 2.07 & 3 & 1.0 & 0.85 \\
lc & -6 & 21 & 540 & 326 & 1.66 & 17 & 0.81 & 0.42 \\
ld & -13 & 25 & 110 & 50 & 2.20 & 4 & 0.16 & 0.32 \\
le & -30 & 40 & 192 & 89 & 2.16 & 7 & 0.18 & 0.19 \\
lf & -38 & 49 & 226 & 105 & 2.15 & 8 & 0.21 & 0.18 \\
\hline
\end{tabular}

${ }^{a} \mathrm{kcal} \mathrm{mol}{ }^{-1},{ }^{b} \mathrm{meV}$.

Figure 4 shows a linear correlation between $\Delta H_{f}^{\prime}(a)$ and the relative dissociation energy $\Delta D\left({ }^{+} \mathrm{C}-\mathrm{X}\right)$ which is expected if the same ion a, $m / z 180$, with a constant $\Delta H_{\mathrm{f}}(\mathrm{a})$ arises from the fragmentations of molecular ions 1a-f. ${ }^{21}$ Again $\Delta H_{\mathrm{f}}{ }^{\prime}(\mathrm{a})$ from $1 a$ fits the correlation much better if it is calculated from the corrected value of $A\left(\mathrm{~m} / z 180^{+}\right)$. No constant value of $\Delta H_{\mathrm{f}}(\mathrm{a})$ is obtained after the correction of the $\Delta H_{f}^{\prime}$ (a) by $T_{\mathrm{B}}$ values, but the $\Delta H_{\mathrm{f}}^{\prime}(\mathrm{a})_{\text {cor }}$ approach the value $220 \mathrm{kcal} \mathrm{mol}^{-1}$, suggesting $\Delta H_{\mathrm{f}}(\mathrm{a}) \leq 220 \mathrm{kcal} \mathrm{mol}^{-1}$. This agrees very well with $\Delta H_{\mathrm{f}}(\mathrm{a})=$ $221 \pm 5 \mathrm{kcal} \mathrm{mol}^{-1}$, which has been calculated independently by the thermochemical data of the hypothetical reaction sequence discussed in the Appendix. Hence $\Delta H_{\mathrm{f}}(\mathrm{a})=220 \mathrm{kcal} \mathrm{mol}^{-1}$ has been accepted for the further calculations.

Energy Partitioning during the Fragmentation. The kinetic energies, $T$, released during the formation of ion a from molecular ions 1a-f and calculated from the peak width at $22\left(T_{22}\right)$ and $50 \%$ $\left(T_{50}\right)$ of the peak height or at the base $\left(T_{\mathrm{B}}\right)$ of the signal are given in Table $\mathrm{V}$ together with $\epsilon_{\mathrm{r}}{ }^{*}$ and the enthalpy of reaction $\Delta H_{\mathrm{R}}{ }^{+}$; $\epsilon_{\mathrm{r}}^{*}$ and $\Delta H_{\mathrm{R}}{ }^{+}$have been calculated according to eq 3 and 4 , respectively.

$$
\begin{gathered}
\epsilon_{\mathrm{r}}^{*}=A\left(m / z 180^{+}\right)+\Delta H_{\mathrm{f}}(\mathrm{M})-\Delta H_{\mathrm{f}}(\mathrm{a})-\Delta H_{\mathrm{f}}(\mathrm{X} \cdot) \\
\Delta H_{\mathrm{R}}^{+}=\Delta H_{\mathrm{f}}(\mathrm{a})+\Delta H_{\mathrm{f}}(\mathrm{X} \cdot)-\Delta H_{\mathrm{f}}(\mathrm{M})^{+} .
\end{gathered}
$$

With the exception of the loss of the fluoro substituent from $\mathbf{1 b}^{+}$, which is associated with only a small amount of $\epsilon_{\tau}^{*}$, large values of $\epsilon_{\mathrm{r}}^{*}$ are obtained for the loss of ortho substituents from the molecular ions of all other compounds investigated, increasing especially for the reactions of $1 \mathrm{e}^{+}$. and $1 \mathrm{ff}^{+}$. However, the large values of $\epsilon_{\tau}^{*}$ are reflected in correspondingly large values of $T$ only in case of the reactions of $1 \mathrm{a}^{+}$. and $1 \mathrm{c}^{+}$, but neither in the $\epsilon_{\mathrm{r}}^{*}$ values nor in the peak shapes of the corresponding signals in the MIKE spectra of 1d, 1e, and 1f. These signals are "flat-topped" in the case of 1a and 1c, indicating a nonstatistical distribution of $\epsilon_{\mathrm{r}}^{*}$ during the kinetic-energy release, whereas the ratio $T_{22} / T_{50}$ is close

(21) Schaldach, B.; Grützmacher, H. F. Int. J. Mass Spectrom. Ion Phys. $1979,31,271$ 
to the value 2.16 expected for a Gaussian peak shape ${ }^{22}$ and indicating a statistical distribution of the kinetic energies released in the case of $1 d-f$. The difference in the reactions between the two classes of derivatives is most clearly seen by a comparison between 1c and 1d. For both compounds similar values of $\epsilon_{\mathrm{r}}{ }^{*}$ have been calculated ( 21 and $25 \mathrm{kcal} \mathrm{mol}^{-1}$, respectively). Whereas a broad, "flat-topped" signal is observed in the MIKE spectra of 1c for the loss of a methyl group indicating a large value of $T$, the Gaussian-shaped signal in the MIKE spectrum of $1 \mathbf{d}$ for the loss of the chloro substituent is rather sharp, corresponding to a small kinetic-energy release.

The two classes of derivatives (and reactions) are clearly distinguished by the energy partitioning quotient $q$, which has been calculated with the aid of the maximum value $T_{\mathrm{B}}$ according to $q=T_{\mathrm{B}} / \epsilon_{\mathrm{r}}^{*}$. A $q=0.71-1.0$ observed for the reactions of $1 \mathrm{a}-\mathrm{c}$ shows that all or most of $\epsilon_{\mathrm{r}}^{*}$ is released as $T$ during the dissociation of a $\mathrm{H}, \mathrm{F}$, and $\mathrm{CH}_{3}$ substituent, respectively, from the molecular ions. However, $q$ drops dramatically and abruptly to $0.16-0.21$ by changing the substituent into a $\mathrm{Cl}, \mathrm{Br}$, or I atom.

A wide range of kinetic energies $T$ and of energy partitioning quotients $q$ has been observed for mass-spectrometric fragmentations and several theoretical models have been used to correlate the kinetic-energy release with the transition state of the reactions. ${ }^{2,4,5,6,23}$ One successful approach has been to calculate the potential-energy surface of the reaction and to follow the movement of the reacting system across this surface. ${ }^{5,6}$ However, a reliable application of these methods to reactions of large oddelectron organic ions is difficult. Hence it is of interest to look for more simple concepts which link the kinetic-energy release to certain properties of the reaction transition states.

One of these properties is seen in the "tightness" of the activated complex since a correlation appears to exist between $q$ and the ring size of the transition state. ${ }^{6,23}$ However, this effect cannot be responsible for the variation of $q$ in the reaction series studied here, because all reactions occur via five-membered transition states with probably very similar geometry. Similarly, the number of internal degrees of freedom in the reacting ions, which is also known to influence the amount of $T,{ }^{23 a-c}$ is not very different for $1 \mathrm{a}-\mathrm{f} .{ }^{24}$

A characteristic feature of the substitution reaction of $1 \mathbf{a}-\mathbf{f}$ is the slight variation of the activation energy $\epsilon_{\mathrm{h}}{ }^{*}$ with the dissociation energy $D\left({ }^{+} \mathrm{C}-\mathrm{X}\right)$, while the enthalpy of reaction $\Delta H_{\mathrm{R}}{ }^{+}$changes by more than $50 \mathrm{kcal} \mathrm{mol}^{-1}$ from endothermic or nearly thermoneutral reactions of $1 \mathrm{a}-\mathbf{e}$ to strongly exothermic reactions of 1e,f (Table V). According to the Hammond postulate ${ }^{25}$ the position of a transition state on the reaction coordinate is different for endo- and exothermic elementary reactions, respectively, with (nearly) constant activation energies. Hence, the sharp decrease in $q$ in spite of increasing $\epsilon_{\mathrm{r}}^{*}$ in the reaction series appears to be due to different positions of the individual transition states on the reaction coordinate.

According to Miller ${ }^{9}$ the position $X_{0}^{*}$ of a transition state is determined by the height of the potential-energy barrier $U^{*}$ (here $\epsilon_{\mathrm{h}}{ }^{*}$ ) and the potential energy $U_{\mathrm{f}}$ of the reaction (here $\Delta H_{\mathrm{R}}{ }^{+}$):

$$
X_{0}{ }^{*}=\frac{1}{2-U_{\mathrm{f}} / U^{*}}=\frac{1}{2-\Delta{H_{\mathrm{R}}}^{+} / \epsilon_{\mathrm{h}}{ }^{*}}
$$

(22) Elder, J. F.; Beynon, J. H.; Cooks, R. G. Org. Mass Spectrom. 1976 11,415 .

(23) (a) Beynon, J. H.; Bertrand, M.; Cooks, R. G. J. Am. Chem. Soc 1973, 95, 1739. (b) Kim, K. C.; Beynon, J. H.; Cooks, R. G. J. Chem. Phys. 1974, 61, 1305. (c) Boyd, R. K.; Beynon, J. H. Int.J. Mass Spectrom. Ion Phys. 1977, 23, 163. (d) Elder, J. F.; Beynon, J. H.; Cooks, R. G. Org. Mass Spectrom. 1975, 10, 273. (e) Florêncio, H,; Vijfhuizen, P. C.; Heerma, W.; Dijkstra, G. Ibid. 1979, 14, 337.

(24) The different peak shapes of the signals of the corresponding metastable transitions hint to a different origin of $T$. The statistical distribution of $T$ associated with a Gaussian peak shape and the small but nearly constant $q=0.18 \pm 0.03$ for $1 \mathbf{d}-\mathbf{f}$ probably indicate that most of $T$ stems from the $\epsilon^{*}$ part of $\epsilon_{\mathrm{r}}^{*}$ (see Figure 2). In contrast, obviously ${ }^{0} \epsilon_{\mathrm{q}}^{*}$ is the main origin of $T$ in the case of $1 \mathrm{a}$ and $1 \mathrm{c}$, as indicated by the large values of $q$ and the "flattopped" form of the signals.

(25) Hammond, G. S. J. Am. Chem. Soc. 1955, 77, 334

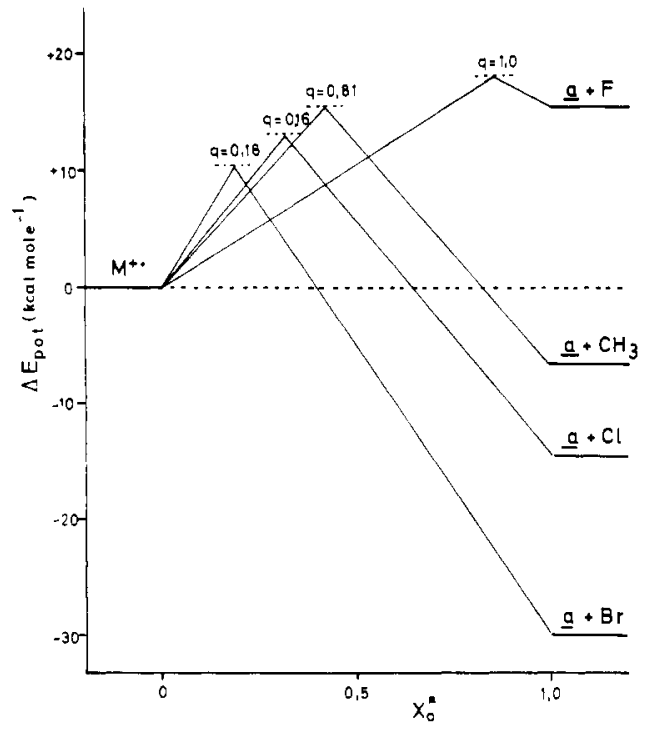

Figure 5. Hammond diagram of potential energy.

The positions $X_{0}^{*}=0$ and $X_{0}^{*}=1$ correspond to the starting and final states of the reaction, respectively. The values of $X_{0}^{*}$ for the fragmentations of the molecular ions $1 a-f$ are given in Table $\mathrm{V}$. They vary parallel to $\Delta H_{\mathrm{R}}{ }^{+}$from 0.85 for $1 \mathrm{~b}$ ("late" transition state) to 0.19 and 0.18 for le and 18 ("early" transition states). Comparing $X_{0}^{*}$ and $q$ in the series (Table V and Figure 5) large energy partitioning quotients of $q=0.7-1.0$ are associated with symmetrical or late positions $\left(X_{0}^{*}=0.4-1.0\right)$ of the transition state while small energy partitioning quotients $q=0.16-0.21$ belong to early positions $\left(X_{0}^{*}<0.4\right)$. Obviously in the first class of reactions $\left(X_{0}^{*}>0.4\right.$, late transition states) most of the energy of the transition state is accumulated in the stretched $\mathrm{C}-\mathrm{X}$ bond and is released as kinetic energy of the product if the stretching of this bond proceeds toward dissociation. In the second class $\left(X_{0}\right.$ $<0.4$, early transition states) only a minor part of the transition-state energy has to be accumulated in the dissociating $C-X$ bond. Hence only a small part is released as kinetic energy of the dissociation products.

The present results for a correlation between energy partitioning and position of transition states fit very well into the fundamental concepts of reaction dynamics, which have been developed by Polanyi, ${ }^{26}$ for the partitioning of $\epsilon_{\mathrm{r}}{ }^{*}$ into kinetic and vibrational energy during bimolecular reactions. From this concept it is predicted that during reactions occurring on an "attractive" potential energy surface with the energy barrier at an early position along the reaction path (reactant-like configuration of the activated complex) a vibrational excitation of the products will be favored. However, most of ${ }^{0} \epsilon_{\mathrm{r}}{ }^{*}$ will be released as kinetic energy during reactions with "repulsive" energy surfaces with a late position of the transition state (product-like configuration of the activated complex). Moreover, this concept predicts that a change between the two modes of energy partitioning will take place quite suddenly, if the crest of the energy barrier is moved along the reaction path from the entry valley to the exit valley of the reaction. ${ }^{26}$ This is exactly what has been observed for the series of intramolecular substitution reactions of the molecular ions $1 \mathrm{a}-\mathrm{f}, X_{0}{ }^{*} \simeq 0.4$ being obviously the critical position of the transition state.

Finally, it should be mentioned that a similar behavior on energy partitioning has been observed by us recently for intramolecular substitutions of the molecular ions of 2-benzoylpyridines ${ }^{1}$ and of benzylacetones. ${ }^{21}$ Although the results are somewhat disturbed by side reactions and are not as clear as for the reactions of the 1-phenyl-1-(2-pyridyl)ethylenes, a change of the $q$ values is also observed at a critical value $X_{0}{ }^{*} \simeq 0.4$. Thus this change in the mode of energy partitioning appears to be a fundamental property of the intramolecular aromatic substitution reactions of these molecular ions, and mass-spectrometric techniques seem to be well

(26) Polanyi, J. C. Acc. Chem. Res. 1972, 5, 161. 
Scheme III

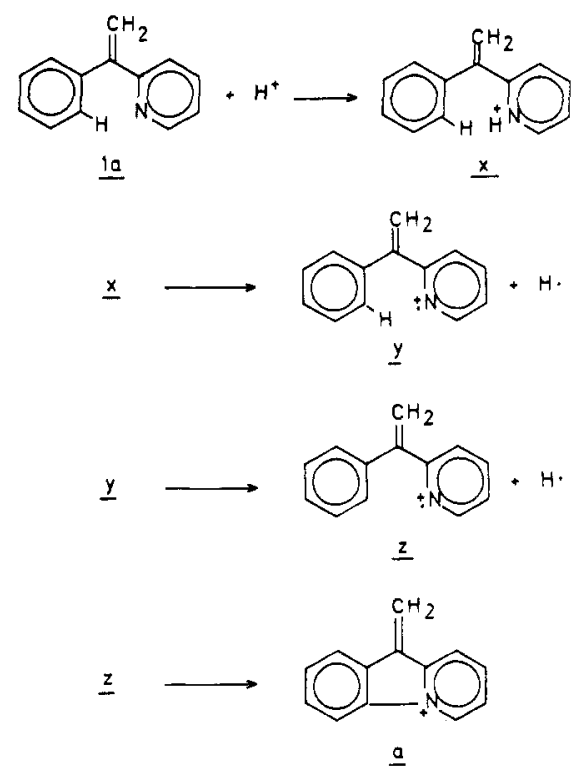

suited to reveal the characteristics of such elementary reactions of complex organic ions.

\section{Experimental Section}

The mass spectra were obtained with a Varian MAT 311A mass spectrometer. Experimental conditions: accelerating voltage, $3 \mathrm{kV}$ electron energy, $70 \mathrm{eV}$; emission current, $2 \mathrm{~mA}$; ion source temperature, $150^{\circ} \mathrm{C}$; ion source pressure, $<2 \times 10^{-6} \mathrm{Torr}$; direct insertion of the sample and sample temperature, $<60^{\circ} \mathrm{C}$.

The kinetic energy $T$ released during the fragmentations has been determined from the appropriate metastable transitions observed on the same instrument and similar experimental conditions by scanning the voltage across the electrostatic analyzer (second field-free region). $T_{50}$ and $T_{22}$ have been calculated from the peak width at the corresponding peak height. ${ }^{3}$ To determine $T_{\mathrm{B}}$ the peaks of the metastable transitions have been approximated by either a triangle or a trapezoid, and the width of the base line has been used for the calculations. All values have been corrected for the width of the main beam. ${ }^{27}$ The reproducibility of the $T$ values is $\pm 10 \%$.

The ionization energies and appearance energies were determined from semilogarithmic plots of ion efficiency curves, ${ }^{28}$ measured with a modified Vacuum Generators MM 12B mass spectrometer (accelerating voltage, $4 \mathrm{kV}$; electron emission current, $20 \mu \mathrm{A}$; ion source temperature, $150^{\circ} \mathrm{C}$ direct insertion of the sample, repeller potential $0 \mathrm{~V})$, using $\mathrm{CH}_{3} \mathrm{I}(I(\mathrm{M})$ $=9.53 \mathrm{eV})^{18}$ as a reference. The values given in the tables are the mean of at least three independent measurements. The reproducibility is $< \pm 0.1$ $\mathrm{eV}$.

The MI spectra and CA spectra were obtained with a Vaccum Generators $\mathrm{ZAB}-2 \mathrm{~F}$ mass spectrometer, modified for measurements at low electron energies and equipped with collision chambers in the first and

(27) Baldwin, M. A.; Derrick, P. J.; Morgan, R. P. Org. Mass Spectrom. $1976,11,440$.

(28) Lossing, F. P.; Tickner, A. N.; Bryce, W. A. J. Chem. Phys. 1951, 19,1254 . second field-free region. He as collision gas was introduced into the appropriate collision chamber at such a rate that the intensity of the main beam dropped to $10 \%$ of its original value. With the exception of the (F $-H)^{+}$ions the reproducibility of the MI and CA spectra is $< \pm 10 \%$.

The 1-phenyl-1-pyridylethylenes (1a-f, 2, and 3) were synthesized via the corresponding 1-methyl-1-phenyl-1-pyridylcarbinols, obtained by reaction of 2-pyridyllithium with the (substituted) benzoylpyridine by standard procedures. The carbinols were purified by vacuum distillation or recrystallization from petroleum ether $\left(\mathrm{bp} 60-70^{\circ} \mathrm{C}\right)$ and dehydrated by dissolving in $\mathrm{CH}_{3} \mathrm{COOH} / \mathrm{H}_{2} \mathrm{SO}_{4}$ at room temperature. After the dehydration was complete (controlled by TLC), the reaction mixture was diluted with water and neutralized with $2 \mathrm{~N} \mathrm{NaOH}$. The mixture was extracted with ether. The 1-phenyl-1-pyridylethylenes were purified by column chromatography (silica, benzene/ethyl acetate, 10:1), yield $10-65 \%$.

Acknowledgments. We are grateful to the Fonds der Chemischen Industrie for financial support of this work.

\section{Appendix. Estimation of $\Delta H_{f}(a)$ by Thermochemical Data}

$\Delta H_{\mathrm{f}}(\mathrm{a})$ can be calculated from the enthalpy changes of the reaction steps $a-d$ of the hypothetical reaction sequence of Scheme III.

$$
\begin{gathered}
\mathrm{PA}(1 \mathrm{a})=\Delta H_{\mathrm{f}}(1 \mathrm{a})+\Delta H_{\mathrm{f}}\left(\mathrm{H}^{+}\right)-\Delta H_{\mathrm{f}}(\mathrm{x}) \\
D(\mathrm{~N}-\mathrm{H})=\Delta H_{\mathrm{f}}(\mathrm{y})+\Delta H_{\mathrm{f}}(\mathrm{H} \cdot)-\Delta H_{\mathrm{f}}(\mathrm{x}) \\
D\left(\mathrm{C}_{\mathrm{ar}}-\mathrm{H}\right)=\Delta H_{\mathrm{f}}(\mathrm{z})+\Delta H_{\mathrm{f}}(\mathrm{H} \cdot)-\Delta H_{\mathrm{f}}(\mathrm{y}) \\
D\left({ }^{+} \mathrm{N}-\mathrm{Ph}\right)=\Delta H_{\mathrm{f}}(\mathrm{z})-\Delta H_{\mathrm{f}}(\mathrm{a})
\end{gathered}
$$

Equations a-d are combined to

$$
\begin{array}{r}
\Delta H_{\mathrm{f}}(\mathrm{a})=\Delta H_{\mathrm{f}}(\mathbf{1 a})+\Delta H_{\mathrm{f}}\left(\mathrm{H}^{+}\right)-2 \Delta H_{\mathrm{f}}(\mathrm{H} \cdot)-\mathrm{PA}(\mathbf{1 a})+ \\
D\left(\mathrm{C}_{\mathrm{ar}}-\mathrm{H}\right)+\left[D\left(^{+} \mathrm{N}-\mathrm{H}\right)-D\left({ }^{+} \mathrm{N}-\mathrm{Ph}\right)\right]
\end{array}
$$

$\Delta H_{\mathrm{f}}(1 \mathrm{a})=70 \mathrm{kcal} \mathrm{mol}^{-1}$ has been calculated from increments ${ }^{19}$ using $\Delta H(1,1$-diphenylethylene $)=58.7 \pm 1.1 \mathrm{kcal} \mathrm{mol}^{-1} 20$ as a starting point. $D\left(\mathrm{C}_{\mathrm{ar}}-\mathrm{H}\right)=104 \mathrm{kcal} \mathrm{mol}^{-1}$ corresponds to the homolytic dissociation energy of a $\mathrm{C}-\mathrm{H}$ bond in benzene; ${ }^{29}$ $\Delta H_{\mathrm{f}}\left(\mathrm{H}^{+}\right)=365.2^{18}$ and $\Delta H_{\mathrm{f}}(\mathrm{H} \cdot)=52.1 \mathrm{kcal} \mathrm{mol}^{-118}$ are accurately known. From the remaining quantities of eq e the proton affinity of 1-phenyl-1-(2-pyridyl)ethylene, PA(1a), is set equal to $\mathrm{PA}$ (pyridine) $=219 \mathrm{kcal} \mathrm{mol}^{-1} 30$ since the styryl substituent is not expected to alter the proton affinity due to the lone electron pair at the $\mathrm{N}$ atom of pyridine very much.

The homolytic dissociation energies $D\left({ }^{+} \mathrm{N}-\mathrm{H}\right)$ and $D\left(^{+} \mathrm{N}-\mathrm{Ph}\right)$ in the pyridinium ions $x$ and $a$, respectively, are not known. Fortunately, only the difference between both dissociation energies has to be known, which is not large. By the use of relevant thermochemical data $\left[D\left(^{+} \mathrm{N}-\mathrm{H}\right)-D\left({ }^{+} \mathrm{N}-\mathrm{Ph}\right)\right]=5 \mathrm{kcal} \mathrm{mol}^{-1}$ has been calculated. 'Insertion of the appropriate values in eq 3 results in $\Delta H_{\mathrm{f}}(\mathrm{a})=221 \mathrm{kcal} \mathrm{mol}^{-1}$. This is in very excellent agreement with the limiting value of $220 \mathrm{kcal} \mathrm{mol}^{-1}$ obtained from $\Delta H_{\mathrm{f}}^{\prime}(\mathrm{a})_{\text {cor }}$ by appearance-energy measurements (Table V). It should be noted that any error in $\Delta H_{\mathrm{f}}(\mathrm{a})$ will introduce a systematic error into the calculations of $\epsilon_{\mathrm{r}}^{*}$ and $q$, but will not influence the variation of $q$ within the reaction series of $1 \mathrm{a}-\mathbf{f}$.

(29) Kerr, J. A. Chem. Rev. 1966, 66, 465.

(30) Freiser, B. S.; Beauchamp, J. L. J. Am. Chem. Soc. 1976, 98, 265. 